Article

\title{
Participatory Climate Change Impact Assessment in Three Czech Cities: The Case of Heatwaves
}

\author{
Eliška Krkoška Lorencová ${ }^{1, *}$, Charlotte E. L. Whitham ${ }^{1}$, Petr Bašta ${ }^{1}$, \\ Zuzana Veronika Harmáčková ${ }^{1}$ (D), Petr Štěpánek ${ }^{1,2}$ (D), Pavel Zahradníček ${ }^{1,2}$, Aleš Farda ${ }^{1}$ and \\ David Vačkáŕr ${ }^{1}$ \\ 1 Global Change Research Institute of the Czech Academy of Sciences, Bělidla 986/4a, 60300 Brno, \\ Czech Republic; whitham.c@czechglobe.cz (C.E.L.W.); basta.petr@gmail.com (P.B.); \\ harmackova.z@czechglobe.cz (Z.V.H.); stepanek.p@czechglobe.cz (P.Š); zahradnicek.p@czechglobe.cz (P.Z.); \\ farda.a@czechglobe.cz (A.F.); vackar.d@czechglobe.cz (D.V.) \\ 2 Czech Hydrometeorological Institute, Brno Regional Office, Kroftova 43, 61667 Brno, Czech Republic \\ * Correspondence: lorencova.e@czechglobe.cz; Tel.: +420-601-383-186
}

Received: 30 March 2018; Accepted: 4 June 2018; Published: 7 June 2018

check for updates

\begin{abstract}
Cities are complex socioecological systems that are particularly vulnerable to the impacts of climate change and are also exposed to other trends, such as urbanization and population aging. Due to the changing climate, days with extreme temperatures are expected to become more numerous, which is particularly important for urban areas, where the urban heat island phenomenon is observed. This study presents an example of a spatially explicit potential climate change impact assessment of heatwaves integrating both science and stakeholder participation for three large Czech cities (Prague, Brno, and Pilsen). Stakeholder participation exercises were used to prioritize climate change risks, provide impetus and opportunity for knowledge co-production, and support adaptation planning. Potential climate change impacts of heatwaves in the three Czech cities for the current baseline (1981-2010) and for the future (2021-2040) using Representative Concentration Pathways (RCPs) - RCP 4.5 and RCP 8.5, were mapped at two levels describing "in-city" and "inter-city" comparison. When comparing the potential impact of heatwaves across the three cities ("inter-city"), the most affected city is Brno, with $10.5 \%$ of its area in the very high impact category for the baseline and both RCPs. The "in-city" comparison shows the differences between the baseline and future scenarios of each city. The assessment of heatwaves' impacts was further used to support urban adaptation planning.
\end{abstract}

Keywords: climate change impact assessment; urban adaptation; heatwaves; Representative Concentration Pathways (RCPs); stakeholder participation; vulnerability assessment framework

\section{Introduction}

Cities, centers of cultural exchange and economic prosperity and home to the majority of the human population, are complex socioecological systems that are particularly vulnerable to the impacts of climate change [1,2]. In addition, cities are exposed to trends that further increase their vulnerability to climate change, such as urbanization, population aging and the concentration of substantial economic assets within the cities [3-5]. Climate change vulnerability and adaptation has been extensively researched during the last decade [6-10].

The vulnerability of urban areas to climate change is expected to rise as a result of urban population growth and increasing climate extremes. In Europe, the share of the population in urbanized areas is projected to expand in all future SSP (Shared Socioeconomic Pathway) scenarios [11]. In the Czech Republic, which represents the focus area of this study, approximately $73 \%$ of the population 
currently lives in cities [12], and this is expected to increase to $80-94 \%$ by 2100 [13]. Due to the changing climate, days with extreme temperatures are expected to become more numerous, which could be particularly important for urban areas where the urban heat island (UHI) phenomenon is observed [14]. A Europe-wide study assessing future changes in heatwave impacts in 571 cities using RCP 8.5 for the future period (2051-2100) showed an increase in heatwave days across all cities compared to the historical period (1951-2000). However, the greatest growth in heatwave temperatures is projected in Central European cities (e.g., Prague, Vienna), with changes of up to $14{ }^{\circ} \mathrm{C}$ [15]. In the Czech Republic, climate change impacts in the future are expected to include an increase in the number and intensity of days with extreme temperatures. During the period 2021-2050, the number of tropical days will increase by $50 \%$, potentially resulting in prolonged heatwaves. The combination of the effects of climate change and those of urban heat islands is expected to multiply in cities [16].

In terms of impacts, such climate trends in increasingly expanding urban areas are of further concern when considering the importance of cities for national economic growth. For instance, in 2014, the country's gross domestic product (GDP) generated within Prague, the Czech Republic's capital city, accounted for $24.3 \%$ of the whole nation's GDP [12]. Furthermore, studies on human health have identified a direct link between climate change-related phenomena such as UHI and higher morbidity and mortality $[17,18]$. For example, elderly people, who currently constitute one-quarter of the Czech population [19], are therefore particularly vulnerable to such climate change impacts.

Overall, measuring and understanding the vulnerability of cities to the potential impacts of climate change-related heatwaves and UHIs have become an increasingly important stage within the development of urban climate change adaptation strategies [20,21]. Vulnerability assessments can contribute to the sustainable governance of cities, with the potential to promote risk-based management and effective adaptation to climate change [22]. Bithas and Christofakis (2006) [23] acknowledge the need to define the environmentally sustainable performance of the cities. From a climate change perspective, urban sustainability is often expressed by indicators related to the carbon emissions [24], or the carbon footprint of a particular urban area [25].

The increase in climate change-related impacts, vulnerability, and exposure demands mitigation and adaptation efforts across all European cities. In EU cities, mitigation activities prevail ( $66 \%$ of cities have a mitigation plan). However, adaptation efforts are continuing, as $26 \%$ of European cities have an adaptation plan and $17 \%$ have joint adaptation and mitigation plans [26].

Furthermore, the overall aim of vulnerability assessments is to provide science-based support to risk-based decision-making, risk governance, and ultimately effective climate change adaptation. Urban vulnerability can be conceptualized and framed in various ways [27]. Romero Lankao and Qin (2011) structured urban vulnerability research into three clusters, such as: (i) vulnerability as impact (defined by exposure, sensitivity, and impacts); (ii) inherent urban vulnerability (examining why and how specific cities or populations are more vulnerable); and (iii) urban resilience (moving to response-capacity building). In designing and executing the most suitable, informative, and effective vulnerability assessments, a substantial need for engaging local stakeholders has been recognized [28,29]. However, we are currently still lacking a clear standardized framework supported by tried and tested examples that would guide the design and execution of vulnerability assessments for urban environments [30,31] to effectively integrate science and stakeholder participation. This is particularly true for urban environments, which, as has been argued, represent a landscape of significance and of potential vulnerability, particularly to the effects of heatwaves and development of UHIs.

This paper presents a participatory, spatially explicit assessment of vulnerability to climate change-induced heatwaves for three case-study cities in the Czech Republic. In addition to the practical applicability of our results in targeting adaptation actions, the research-related novelty of this study is twofold. First, recognizing the value of stakeholder participation in vulnerability assessments, we combined climate modeling and impact assessment with the knowledge and experience of local stakeholders and experts. Second, considering that climate change vulnerability assessments in urban 
areas have been extremely scarce in Central and Eastern Europe, this study strives to fill an important research gap. The analyses presented here were based on climate data, the current baseline (1981-2010), and future Representative Concentration Pathways (RCPs) - RCP 4.5 (medium variant of increasing greenhouse gases) and RCP 8.5 (high emission trajectory) — for the period 2021-2040.

\section{Materials and Methods}

This paper builds on a comprehensive approach integrating information from climate change impact assessment with a participative stakeholder process for three major urban areas in the Czech Republic-Prague, Pilsen, and Brno-for the period 2021-2040 (with middle year 2030). The results of this process were subsequently fed into a spatially explicit assessment of potential climate change-related impacts of heatwaves. By using spatially explicit indicators for exposure and sensitivity, we identified hotspots of major climate change-induced impacts within the three cities, i.e., areas where adaptation actions would be most needed.

\subsection{Case-Study Cities-Prague, Pilsen, and Brno}

Three large cities in the Czech Republic, Prague, Pilsen, and Brno (Figure 1), were selected as case-study areas. These three cities concentrate almost $20 \%$ of the entire Czech population and are centers of considerable economic activity (for more details, see Table 1). These three cities were selected as pilot cities for the UrbanAdapt project (http:/ / urbanadapt.cz/en), which aims to develop urban adaptation strategies while supporting ecosystem-based approaches to adaptation.

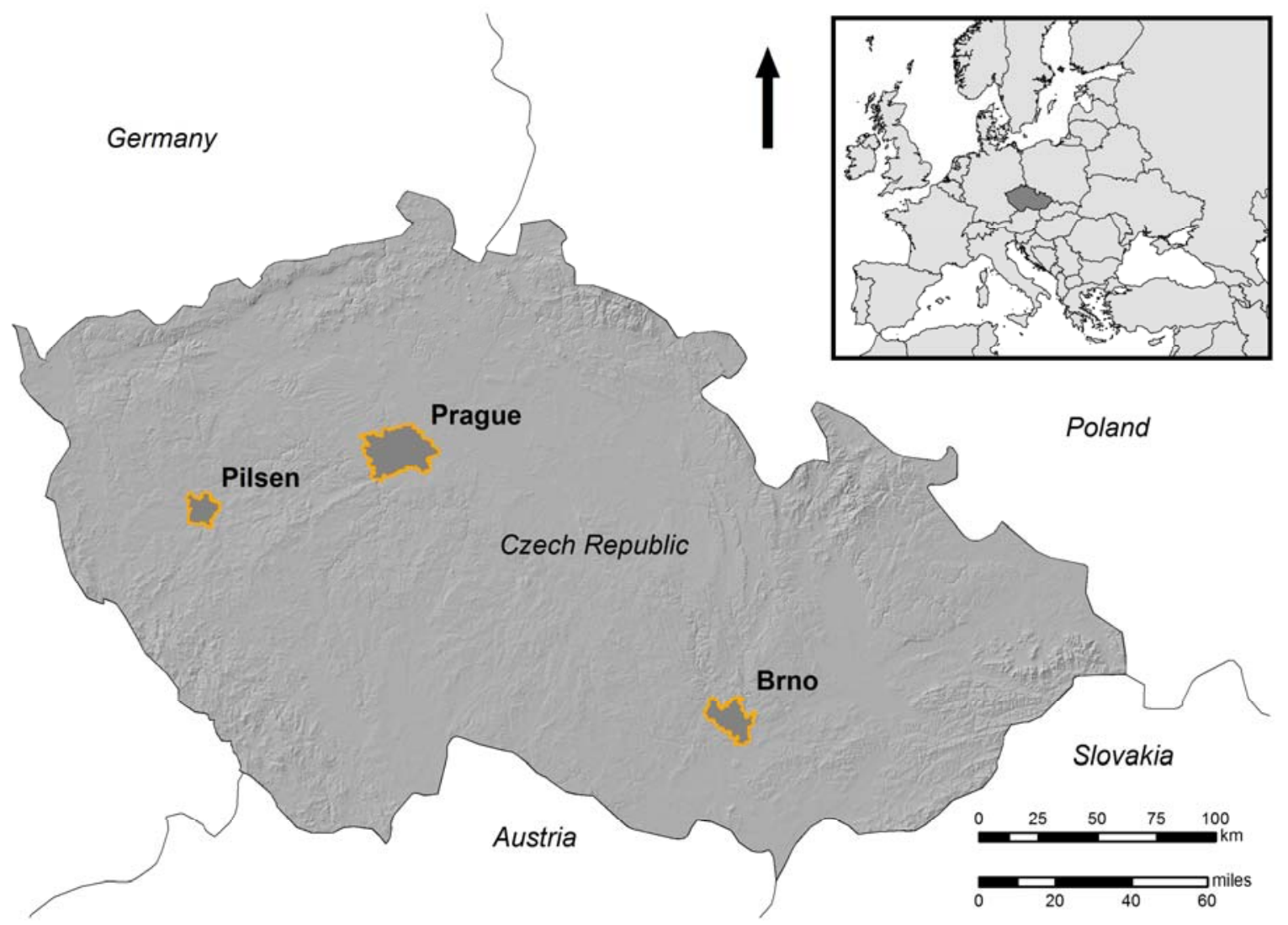

Figure 1. Location of the three case-study cities within the Czech Republic. 
Table 1. Case study-cities-general characteristics.

\begin{tabular}{|c|c|c|c|}
\hline & Prague & Pilsen & Brno \\
\hline $\begin{array}{l}\text { Population } \\
\text { (city/metropolitan area) }^{\text {a }}\end{array}$ & $\begin{array}{c}1,280,508 / 1,999,732 \\
\text { (1st in CZE/1st in CZE) }\end{array}$ & $\begin{array}{c}189,131 / 309,395 \\
\text { (4th in CZE/7th in CZE) }\end{array}$ & $\begin{array}{c}\text { 377,973/609,114 } \\
\text { (2nd in CZE/3rd in CZE) }\end{array}$ \\
\hline $\begin{array}{l}\text { Area (city/metropolitan } \\
\text { area) }\end{array}$ & $496 \mathrm{~km}^{2} / 4983 \mathrm{~km}^{2}$ & $138 \mathrm{~km}^{2} / 1,364 \mathrm{~km}^{2}$ & $230 \mathrm{~km}^{2} / 1755 \mathrm{~km}^{2}$ \\
\hline Climate regions ${ }^{b}$ & warm & warm & $\begin{array}{l}\text { (very) warm with low } \\
\text { precipitation }\end{array}$ \\
\hline $\begin{array}{l}\text { Average annual air } \\
\text { temperature }^{c}\end{array}$ & $8.1-11.0^{\circ} \mathrm{C}$ & $8.1-10.0^{\circ} \mathrm{C}$ & $8.1-11.0^{\circ} \mathrm{C}$ \\
\hline $\begin{array}{l}\text { Average annual amount of } \\
\text { precipitation }{ }^{c}\end{array}$ & $400-550 \mathrm{~mm}$ & $501-600 \mathrm{~mm}$ & $400-600 \mathrm{~mm}$ \\
\hline $\begin{array}{l}\text { Number of tropical days } \\
(1981-2010)\end{array}$ & 11.5 & 12.3 & 12.3 \\
\hline $\begin{array}{l}\text { Number of tropical nights } \\
(1981-2010)\end{array}$ & 0.6 & 0.2 & 0.6 \\
\hline $\begin{array}{l}\text { Number of heatwaves } \\
(1981-2010)\end{array}$ & 5.2 & 6.4 & 7.1 \\
\hline
\end{tabular}

\subsection{Stakeholder Participation in Vulnerability Assessment}

Stakeholder participation played an important role in the methodological approach adopted in this study and provided information which could feed into the components of the vulnerability assessment framework. Two stakeholder workshops and a roundtable discussion were organized for each case-study city, providing invaluable insights into these components. Figure 2 shows the overview of the urban adaptation planning process and the role of participatory workshops and stakeholder inputs, where stakeholder contributions mainly included input for the vulnerability analysis, such as prioritization of climate change-related risks and mapping of vulnerable areas in the given city (particularly with respect to heatwaves and UHIs).

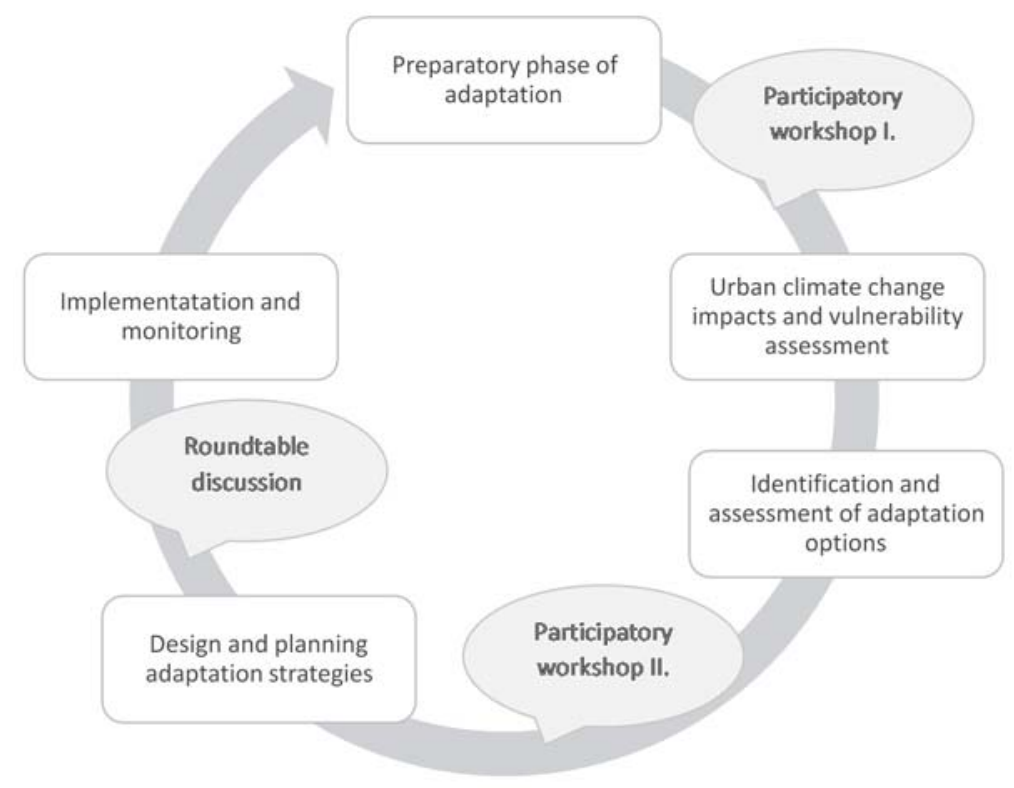

Figure 2. Stakeholder input during the process of urban adaptation planning. 
At the later stage, during the second participatory workshop and roundtable discussions, stakeholders identified challenges and opportunities for urban adaptation and provided feedback on the draft adaptation strategy. In this paper, we focused mostly on the links of the first participatory workshops with the vulnerability analysis by exploring the stakeholders' views and prioritization of climate change-related risks (which were used as the input for analyzing climate change impacts), as well as stakeholders' mapping of vulnerable areas (which was used for verifying quantified outputs from the potential climate change impact assessment).

The participatory workshops were organized to include a wide spectrum of actors (see Table 2) and local stakeholders and to also initiate the process of knowledge exchange and dialogue to support stakeholders in taking future action. Participants were chosen through a stakeholder analysis and networks of municipal partners and were invited using electronic invitations. Within the timeframe of seven months, two participatory workshops were organized in each of the pilot cities. Between the workshops, follow-up research activities were undertaken to help integrate workshop findings into the overall vulnerability assessment framework (Figure 2).

Table 2. Workshops and stakeholder composition.

\begin{tabular}{|c|c|c|c|}
\hline & Prague & Pilsen & Brno \\
\hline Date of 1st workshop & 20 April 2015 & 21 April 2015 & 24 April 2015 \\
\hline Number of participants & 36 & 36 & 41 \\
\hline Stakeholder groups & & & \\
\hline City Hall and Municipal Districts & 8 & 12 & 15 \\
\hline Regional Authority & NA & 2 & 3 \\
\hline Public service providers & 6 & 5 & 3 \\
\hline NGOs & 7 & 4 & 7 \\
\hline Entrepreneurs & 2 & 4 & 5 \\
\hline Academia & 13 & 9 & 8 \\
\hline Date of 2nd workshop & 25 November 2015 & 24 November 2015 & 3 December 2015 \\
\hline Number of participants & 55 & 39 & 40 \\
\hline
\end{tabular}

The workshops were organized into focus groups [32] and their composition was carefully varied with regard to balanced stakeholder representation in order to get a good mix of professions and experience. The majority of workshop participants included representatives of municipal and regional authorities; government and private-sector representatives; and representatives of academia, research institutes, and non-governmental organizations. Each focus group had a facilitator who led the discussion.

During the first workshops (in April 2015), participants were asked to assess the relevance of climate change-related risks and hazards, as well as related impacts, from a temporal perspective by using a five-point scale (where 0 was not relevant at all and 4 was very relevant) for the current situation and the future situation in 2030. The assessed climate change-related problems included heatwaves, urban heat islands, floods, high surface runoff, heavy rains, storms, decrease of groundwater levels, and increased demand for drinking water $[16,33]$. The participants were encouraged to add any other climate change-related problems they considered relevant. The participants were also asked to provide spatial information regarding the location of areas of the cities that are vulnerable to climate change. A further goal of these first workshops was to familiarize participants with the consequences of climate change impacts in their cities and to facilitate identification of their subsequent adaptation needs. Based on the prioritization of climate change-related problems during the first stakeholder workshops, an assessment of the potential impacts of heatwaves was conducted. Moreover, the stakeholders' mapping of climate change-related problems (e.g., heatwaves and UHIs) was used as an external input for verification of our assessment. 


\subsection{Vulnerability Assessment Framework}

The methodological approach used for this assessment of potential climate change impacts was framed within a vulnerability assessment involving a combination of climate modeling and spatially explicit analysis of the cities. In order to assess the potential climate change impacts of heatwaves within our three cities-Prague, Pilsen, and Brno- the framework included exposure and sensitivity to the climate change-related phenomenon of heatwaves (see Figure 3). This framework (adapted from [33-35]) covers several dimensions: exposure and sensitivity (Section 2.4) to climate change leading to a potential climate change impact (Section 2.5), which, together with adaptive capacity, constitute urban vulnerability. Moreover, the adaptation measures and adaptive capacity represent the urban planning dimension supporting urban resilience, which represents scope for potential further research.

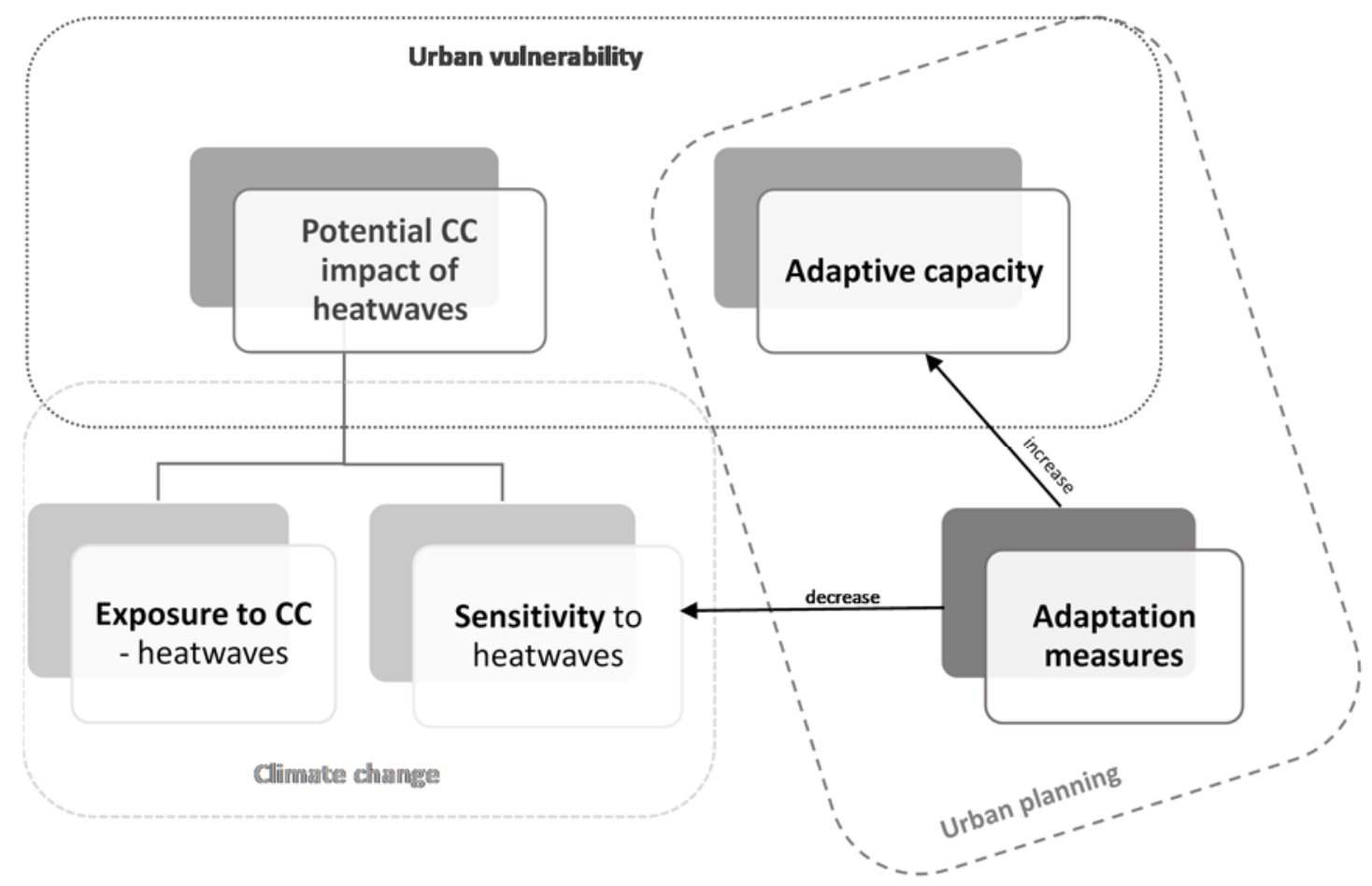

Figure 3. Vulnerability assessment framework (adapted from [33-35]).

As expressed in this framework (Figure 3), urban planning thus plays an important role in identifying what adaptive measures can or will be taken in order to reduce the identified climate change impacts, thus increasing the actual adaptive capacity of the system in question.

\subsection{Input Data and Climate Modeling}

Climate change exposure is directly linked to climate variability through parameters such as the character, magnitude and rate of change, and variation in the climate. This can be expressed by temperature, precipitation, the and occurrence of extreme events (such as heavy rain and meteorological droughts). In our case, we used the climatic indicator of heatwaves.

Sensitivity to climate change determines the degree to which a system is adversely or beneficially affected by a given climate change exposure $[3,33,36]$. This is shaped by natural, physical, human, and society-related attributes. Appropriate indicators were selected to measure the exposure and sensitivity of heatwave impacts in urban areas (Table 3). Selection was based on experience from the literature, [20,31,33], as well as data availability at the local and municipal district levels. 
Table 3. Input data (sensitivity and exposure indicators) for heatwave impact assessment: example for the Prague case study.

\begin{tabular}{llll}
\hline Indicator & \multicolumn{1}{c}{ Input Data } & \multicolumn{1}{c}{ Data Source } & \multicolumn{1}{c}{$\begin{array}{c}\text { Data } \\
\text { Specification/Resolution }\end{array}$} \\
\hline \multirow{2}{*}{ Exposure } & Heatwave indicator & $\begin{array}{l}\text { EURO CORDEX scenarios: baseline } \\
(1981-2010), \text { future RCP 4.5 and } \\
\text { RCP 8.5 (2021-2040) }\end{array}$ & 500 m resolution \\
\hline \multirow{2}{*}{ Sensitivity } & Population density & $\begin{array}{l}\text { CZSO-Statistical Yearbook of } \\
\text { Prague, 2014 }\end{array}$ & Municipal district level \\
\hline & Elderly population (\% of & CZSO-Statistical Yearbook of & Municipal district level \\
& people over the age of 65) & Prague, 2014 & Municipal district level \\
\hline & Share of urban green spaces & Master Plan of the City of Prague & Municipal district level \\
\hline
\end{tabular}

In our case, heatwaves are defined as three consecutive days with a maximum temperature higher than $30^{\circ} \mathrm{C}$. For the analysis of future heatwave impacts (i.e., exposure indicator, Table 1), we used the most recent climate models, which were based on the CORDEX initiative. The EURO CORDEX activity (http: / / www.euro-cordex.net) provides climate simulations at a $12 \mathrm{~km}$ resolution and covering the greater European area including parts of the Middle East, North Africa, and Greenland. This activity is closely linked to the coordinated climate model experiments used in the Couple Model Intercomparison Project (CMIP5) (Taylor et al., 2012) dealing with future climate simulations based on Representative Concentration Pathways (RCPs) emission projections. Three regional climate models were considered in this study (including EC-EARTH RACMO22, MOHC-HADGEM2, MPI-ESM) for two projections, RCP 4.5 (medium variant of increasing greenhouse gases) and RCP 8.5 (high emission trajectory), for the timeframe 2021-2040 [37,38]. For the purpose of this study, it was necessary to process the daily data because of the selected climatic characteristics that were thus calculated.

Since these models contain biases, it was necessary to statistically correct their outputs. First, model outputs were compared with measured values in meteorological stations [39,40] for the control run period (validation phase). Climate models themselves cannot interpret UHIs because they are too general and have a low spatial resolution that does not sufficiently cover the cities. Due to that fact, the regular network was corrected by the network of meteorological stations measuring in the city centers and in suburban areas. Therefore, we are also able to analyze UHIs for the future climate. Based on the model and reference dataset differences, we applied our own correction method based on quantile mapping correction [41,42] for adjusting the model outputs to station locations (correction/localization phase). After the correction, climatological characteristics such as heatwaves, number of tropical days, number of tropical nights, number of days with precipitation totals greater than $20 \mathrm{~mm}$, and annual precipitation sums were calculated and interpolated into maps with a $500 \mathrm{~m}$ resolution. For each RCP, the mean from the three climate models was calculated. For the purposes of this study, a heatwave was defined as a period of at least three consecutive days with temperatures above $30^{\circ} \mathrm{C}$. A tropical day was considered a day with a maximum temperature higher than $30^{\circ} \mathrm{C}$. A very important characteristic for studying urban climate is the number of tropical nights [43]. This was defined as a day with a minimum temperature higher than $20^{\circ} \mathrm{C}$, which implies a very hot night.

\subsection{A Spatially Explicit Method Assessing the Impact of Heatwaves in the Cities}

A spatially explicit method was used for analyzing potential climate change impacts for our three case-study cities. This was based on the approach of Rannow et al. (2010) and Araya-Muñoz et al. (2016) taken in ArcGIS 10.4.1. Firstly, instead of applying a direct classification scale (e.g., low/medium/high), 
all exposure and sensitivity values were normalized to a 0-1 range (Equations (1) and (2)) to enable further indicator comparison.

$$
\mathrm{s}_{\mathrm{x}}=\frac{\mathrm{x}_{\mathrm{i}}-\mathrm{x}_{\min }}{\mathrm{x}_{\max }-\mathrm{x}_{\min }}
$$

A linearly increasing fuzzy membership function (Equation (1)) was applied to positive indicators such as percentage of urban green spaces that can reduce the impact of heatwaves. $x_{i}$ refers to the original value of the indicator; $x_{\min }$ and $x_{\max }$ refer to the respective minimum and maximum values to enable better comparison between the baseline and scenario datasets for each city. A small value of $s_{x}$ thus meant that this indicator strongly contributed to the heatwave impact and, conversely, a high value was associated with a small contribution. If $x_{i}$ is equal to $x_{\max }, s_{x}$ reaches 1 (the smallest heatwave impact); if $x_{i}$ is equal to $x_{\min }, s_{x}$ is 0 (the biggest impact).

$$
\mathrm{s}_{\mathrm{x}}=\frac{\mathrm{x}_{\max }-\mathrm{x}_{\mathrm{i}}}{\mathrm{x}_{\max }-\mathrm{x}_{\min }}
$$

A linearly decreasing fuzzy membership function (Equation (2)) was applied to negative indicators, which increase the heatwave impact (e.g., percentage of built-up areas). The scale for $\mathrm{s}_{\mathrm{x}}(0-1$ range) has the same interpretation as in Equation (1).

Two types of comparison between the pilot cities (Prague, Brno, Pilsen) were made. The first one is the "inter-city" comparison (comparison between the cities), where both $x_{\min }$ and $x_{\max }$ for each indicator were evaluated as a total minimum and maximum within all three pilot cities, with the aim of comparing all three cities to each other.

The second type represents the "in-city" comparison (comparison within a particular city), where $x_{\min }$ and $x_{\max }$ are evaluated for each city separately. This means that the same $s_{x}$ value for Prague can have a different heatwave contribution than the same $s_{x}$ value in Brno and comparison is relevant for the impact assessment within the particular city.

The final assessment of the potential impact of heatwaves involved combining sensitivity and heatwave data using the fuzzy gamma overlay tool with a gamma factor (Equation (3)).

$$
\text { Impact of heatwaves }=\mu_{\text {sum }}^{\gamma} \cdot \mu_{\text {product }}^{1-\gamma}
$$

where $\mu_{\text {sum }}$ is the fuzzy sum, $\mu$ product is the fuzzy product, and $\gamma$ is the gamma factor parameter. $\mu_{\mathrm{i}}$ is the ith membership function of the fuzzy set. The result has the same range (0-1) and interpretation as the partial indicators in Equations (1) and (2). The use of a fuzzy gamma overlay allows an exploration of the relationships between the multiple input criteria and was chosen in order to minimize the omitted information coming from the overlay, which is based on the sum or product algorithm [44]. The gamma factor range is within $0-1$, where for gamma values between 0.6 and 0.8 , the resulting determinant aggregation falls within the entry criteria values [45]. Therefore, for the purpose of our study, the utilized gamma value was 0.8 .

\section{Results}

\subsection{Stakeholders' Assessment of Climate Change-Related Problems}

Stakeholders played an important role in the overall vulnerability assessment as they are, in most cases, the decision-makers, who can support the integration of climate change issues into the local urban policies, strategic, and spatial planning. During the first participatory workshops, stakeholders were provided with scientific information regarding climate change in the Czech Republic, including current status and future climate projections, as well as potential climate change risks in urban areas.

The introductory part on climate change was followed by participatory evaluation. Stakeholders were divided into three groups (each group had a facilitator and note taker) and were asked to rank particular climate change-related problems for the current and future (year 2030) perspective. Climate change-related problems included heatwaves, urban heat island, floods, high surface runoff, heavy 
rains, windstorms, decrease of groundwater levels, and increased demand for drinking water. Firstly, the ranking was performed individually, and then the whole group discussed particular problems and together agreed on the ranking. Finally, problem relevance for a particular city was calculated based on the average value of the three discussion groups.

As a result of the first workshop, heatwaves and urban heat islands (UHI) were perceived as two of the most relevant climate change-related problems currently and in the future in both Prague and Brno (Figure 4). Additionally, in both cities, the problem relevance of heatwaves was perceived to increase in the future (2030). During the discussions in Brno, participants also mentioned the issue of negative impacts of heatwaves and extreme temperatures on human health, projected increase in vulnerable population (particularly elderly people), and potential increase of urban population due to climate change-related migration. In Pilsen, heavy rains, storms, and floods had the highest scores, followed by urban heat islands and heatwaves. Participants also perceived the growing relevance of heatwaves and UHI in the future. Some of the participants mentioned the need for a more detailed knowledge of Pilsen city climatology that is currently not available.

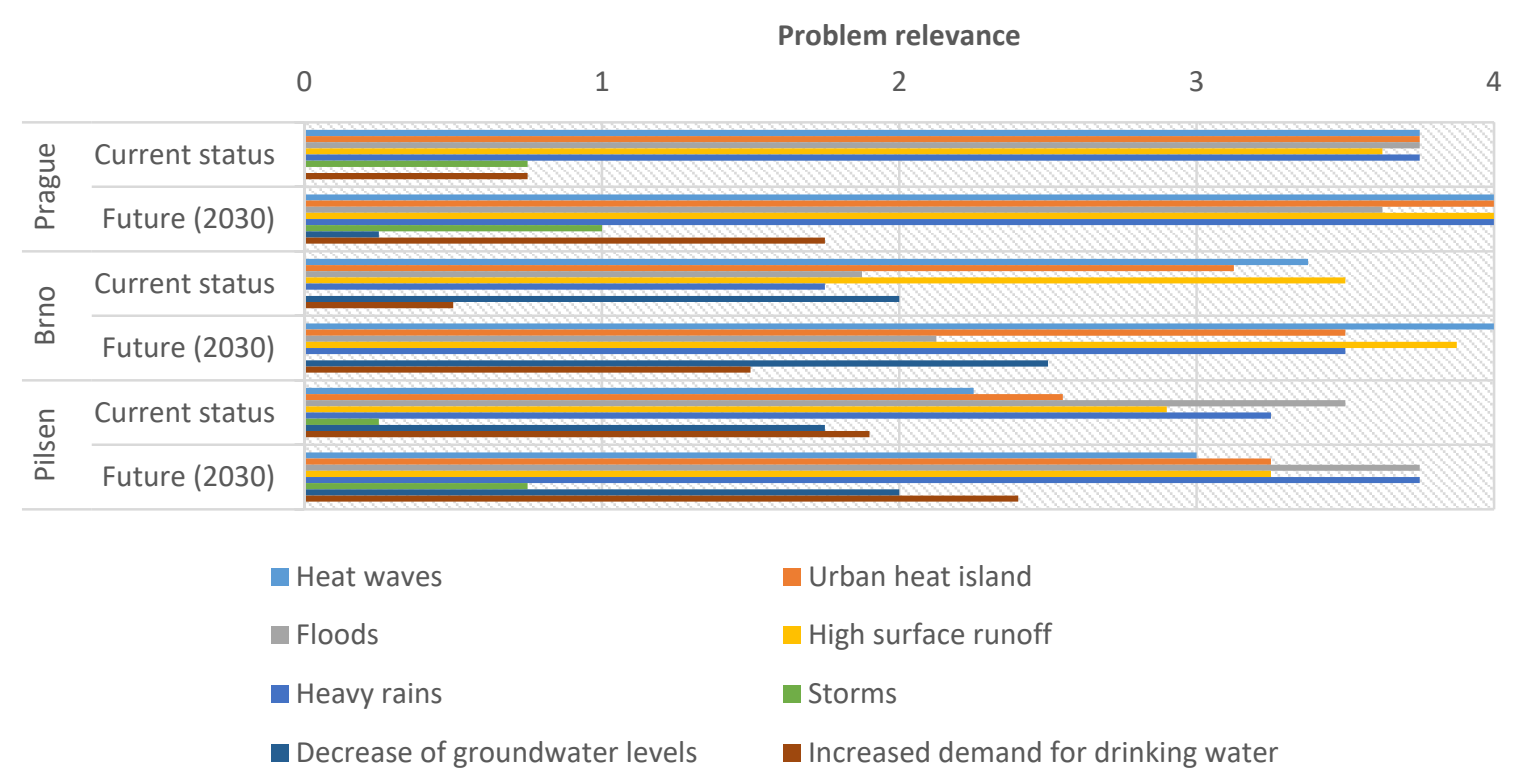

Figure 4. Stakeholders' perceptions of the most relevant climate change-related problems in Prague, Brno, and Pilsen (Scale: 0—not relevant, 4-very relevant).

Stakeholders were also asked to map the areas with a high climate impact. From the spatial perspective, stakeholders identified the most vulnerable areas in terms of heatwaves and risk of urban heat islands. In Prague, these areas indicated by stakeholders included the historical city center (particularly the densely built-up area around the Vltava river) and the built-up areas with large housing estates and blocks of flats. In Brno, stakeholders identified the most vulnerable areas in the city center and in the area of the Brno Exhibition Center, as well as in the industrial areas in the southern part of the city. In Pilsen, the problem of heatwaves and urban heat islands did not receive the highest priority. As the city of Pilsen lies at the confluence of four rivers, floods and heavy rains that could cause flooding were perceived by stakeholders as the most relevant problems. However, from the spatial perspective, stakeholders identified the areas most vulnerable to heatwaves and subsequent urban heat islands within the industrial areas in the city center (Pilsner Urquell brewery and the Škoda machinery factory). In all three cities, heatwaves and urban heat islands were perceived as very relevant climate change-related problems in the future (2030). 


\subsection{Mapping Potential Impacts of Heatwaves in the Pilot Cities}

Based on the fact that significant priority was given to the problems of heatwaves and urban heat islands in the three Czech cities, the impacts of heatwaves currently and in the future (for 2030 and under RCP) were spatially analyzed. Using the methodological procedures described in detail in Section 2.5, we combined exposure and sensitivity indicators for the three cities in order to analyze the potential impacts of heatwaves. The spatial distribution of heatwave impacts was mapped based on the baseline (1981-2010) and RCP 4.5 and RCP 8.5 for the near-term future (2021-2040).

Regarding climatic data, the first part of climate modeling undertaken in this study tested for significant differences between the listed climatic characteristics measured across future climate projections. Overall, no significant differences were observed between emission projections RCP 4.5 and 8.5 in the period 2021-2040, though for the distant future (2081-2100), a significantly higher increase of values was predicted by RCP 8.5 .

In the recent period 1981-2010, the largest number of days of heatwaves was observed in Brno (7.1 days), followed by Pilsen (6.4 days) and Prague (5.2 days). The number of such days will increase by two to three days per year in the near future (2021-2040) under both emission projections. More significant increases are expected by the end of the century. In 2081-2100, the number of heatwave days will be two times higher under RCP 4.5 and five times higher under RCP 8.5, compared with the baseline (1981-2010).

In the period 1981-2010, twelve tropical days per year were observed in the three pilot cities. An increase of two to three days per year will occur in the near future (2021-2040). In the distant future (2081-2100), a significant increase is predicted: in RCP 4.5, 20-22 tropical days per year and, in RCP $8.5,39-42$ tropical days per year, will be experienced in all three cities. Indeed, in 2015, we observed a similar number of tropical days as predicted under RCP 8.5 for the distant future. In recent years, we have observed the largest number of tropical nights in Prague and Brno. On average, one tropical night occurred every two years. The conditions are much better in Pilsen, as a tropical night is observed only once every five years. In the distant future, the highest increase in the occurrence of tropical nights was observed for Brno: to four (RCP 4.5) and 17 (RCP 8.5) nights respectively per year.

The impact of heatwaves in Prague, Pilsen, and Brno was analyzed and mapped at two levels. Firstly, the "inter-city" comparison serves for showing the differences between all three cities on one scale consisting of five regular intervals (see Section 3.2.1). Secondly, the "in-city" comparison (see Section 3.2.2) shows values representing the impact of heatwaves in each particular city defined as quantiles within each city separately (according to the baseline quantile classification in each of the cities). The highest impacts are values close to 0 , where the highest values of exposure to heatwaves and the highest sensitivity intersected based on the fuzzy gamma overlay (for more details, see Section 2.5).

\subsection{1. "Inter-City" Comparison: Potential Climate Change Impact of Heatwaves}

Within the inter-city comparison (comparison between the three pilot cities), for each indicator, a total minimum and maximum were evaluated within all three pilot cities (for more details, see Section 2.5).

Figure 5 shows a comparison of the potential climate change impact of heatwaves between the three pilot cities (Prague, Brno, and Pilsen) for the baseline in 2015 and the RCP 4.5 and RCP 8.5 in 2030. When comparing the potential impact of heatwaves across the three cities, the most affected city is Brno, followed by Prague, with very high (0.0-0.2) and high (0.2-0.4) heatwave impact areas located mainly in the city centers, which corresponds to the mapping outcomes from the participatory workshops (see Section 3.1). In 2030, a growing trend is apparent, particularly in high impact areas in both cities under the RCP 4.5 and 8.5 projections. 


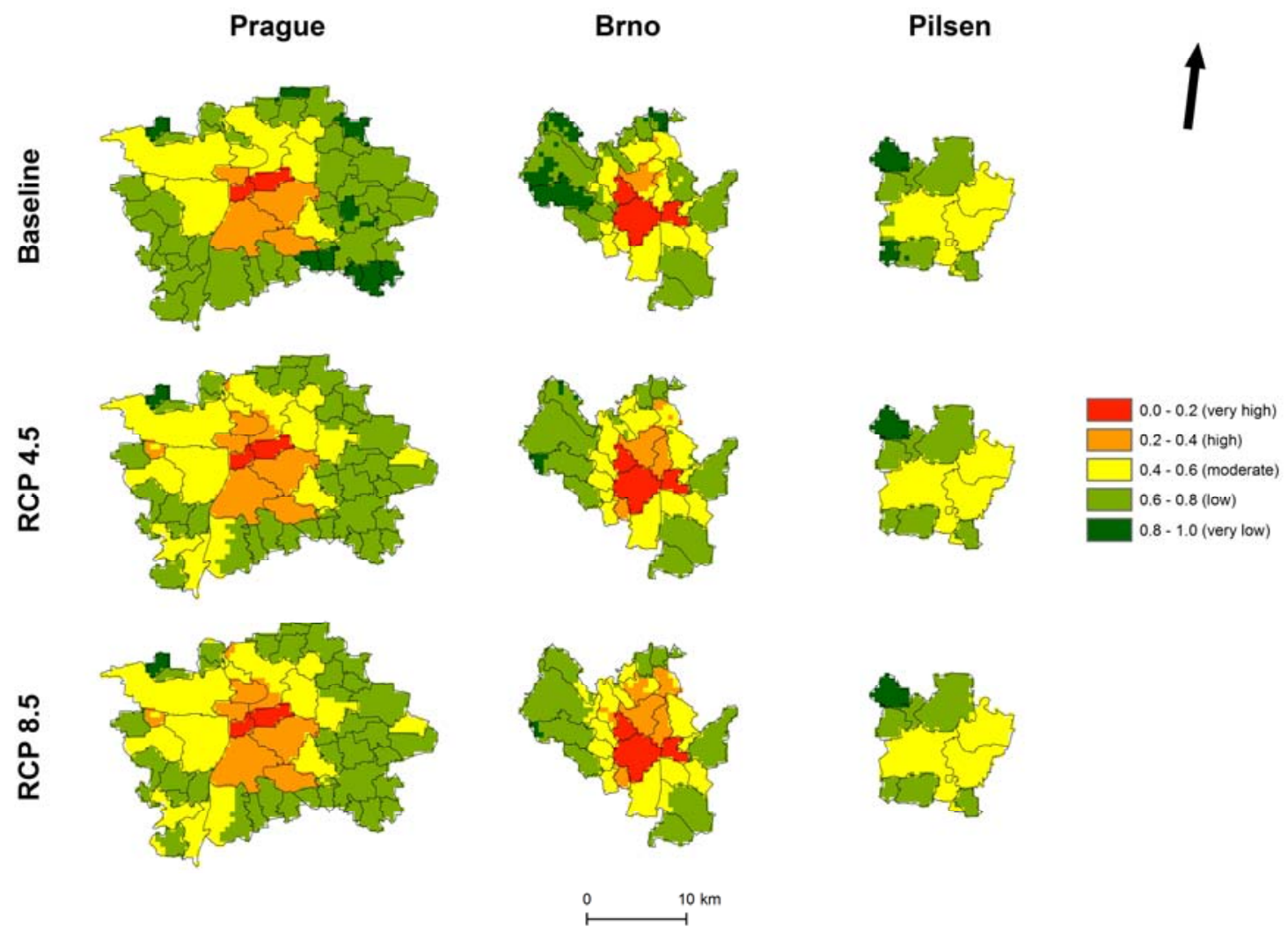

Figure 5. Inter-city comparison of potential climate change impacts of heatwaves in Prague, Brno, and Pilsen for the baseline (2015) and RCP 4.5 and RCP 8.5 (2030).

Moreover, Brno also has the highest area of the very high impact category (0.0-0.2), which covers $10.5 \%$ of the city's area in the baseline and both RCPs. The impacts of heatwaves are more significantly pronounced in 2030, under both RCPs; together, the area of very high and high impact covers approximately one-fifth of Brno (23.5\% under RCP8.5, $19.6 \%$ under RCP 4.5). Concerning the RCP 8.5 high-emission projection, the high impact category covers $12.9 \%$ of the area of Brno (an increase of $9.3 \%$ compared with the baseline). In RCP 4.5 , the high heatwave impact area covers $9.1 \%$ of the city (an increase of 5.5\%). The increase is particularly evident in the northern area of the city center, where the proportion of the built-up area is already relatively high.

In the case of Prague, the very high impact areas remain stable across the baseline and RCP projections, covering $2.1 \%$ of the city's area. However, the high impact areas increase by approximately $3 \%$ under both RCPs ( $2.8 \%$ under RCP $4.5,3 \%$ under RCP 8.5$)$. These areas are located mainly in the city center, with a small fringe in the western part of Prague (see Figure 5).

In contrast, within the inter-city comparison, Pilsen shows the lowest impacts of heatwaves for the baseline, as well as both RCPs. There are only slight changes in the particular impact categories. Categories of very high (0.0-0.2) and high impact (0.2-0.4) are not represented under the baseline and RCPs. The moderate category shows a slight increase in RCP 4.5 and 8.5 (1.8\% and $2.2 \%$, respectively). In both scenarios, the area of very low heatwave impact in the city declines by $2.9 \%$ (Figure 6 ). 
Heatwave impact baseline (2015)

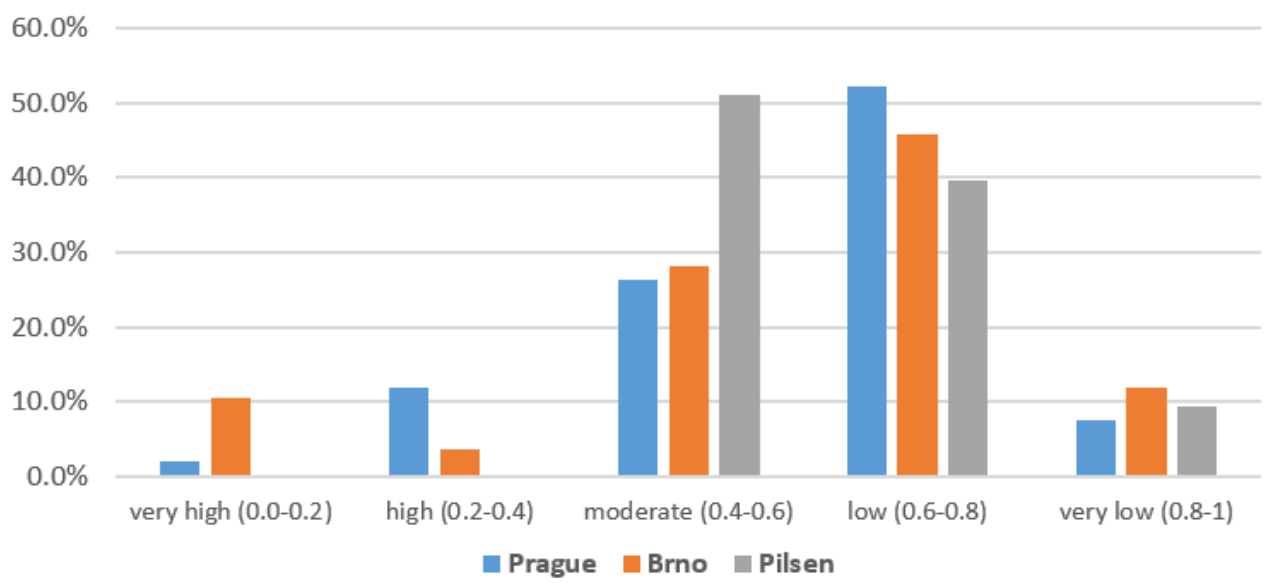

(a)

Heatwave impact RCP 4.5 (2030)

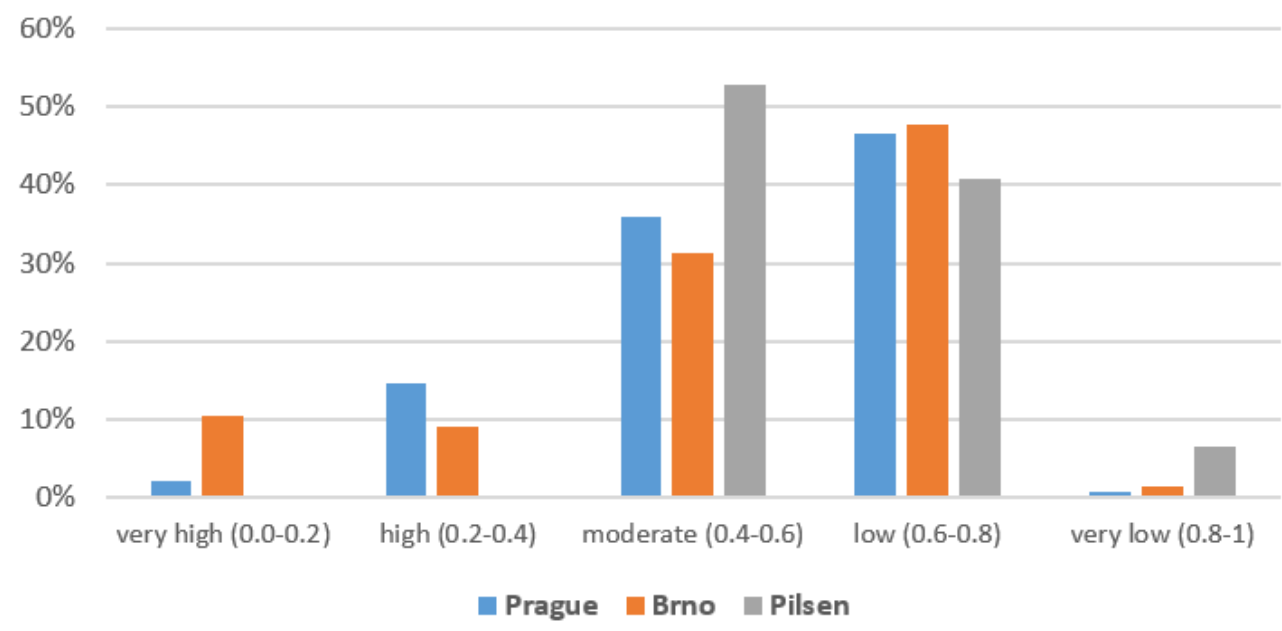

(b)

Heatwave impact RCP 8.5 (2030)

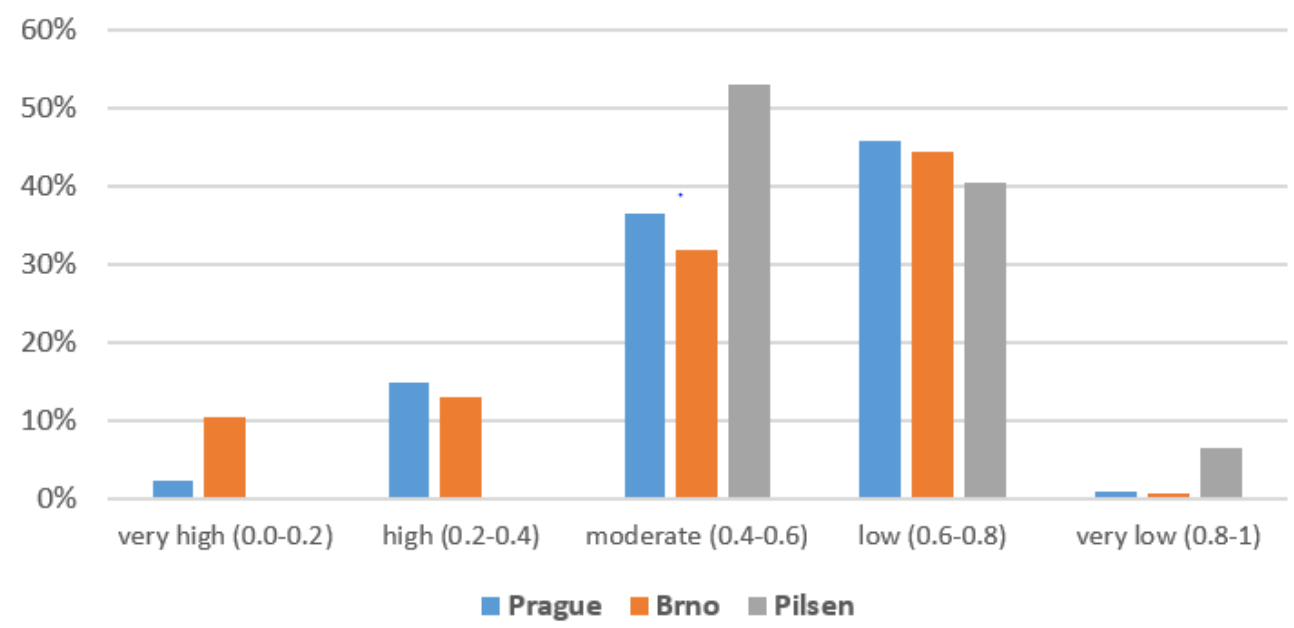

(c)

Figure 6. Inter-city comparison (Prague, Brno, and Pilsen) of potential heatwave impact categories: (a) baseline (2015); (b) RCP 4.5; (c) RCP 8.5. 


\subsection{2. "In-City" Comparison: Potential Climate Change Impact of Heatwaves}

Within the in-city comparison, values representing both exposure and sensitivity were rendered as quantiles within each city based on the baseline quantile classification with the aim of highlighting the differences between baseline and future scenarios within each of the three cities (for more details, see Section 2.5).

\section{City of Prague}

When comparing the potential climate change impacts of heatwaves within Prague for the baseline and RCP projections in 2030, a similar trend is evident for both future RCPs in the increase of areas with a high impact. The assessment shows substantial increase in the area of the highest impact (0-0.43) in both RCP projections in Prague. Compared with the baseline, the increase in the highest impact is $9 \%$ under RCP 4.5 and $9.5 \%$ under RCP 8.5 , particularly in the areas of the city center and the northwestern part of the city. Simultaneously, the second highest impact category $(0.43-0.60)$ increases by approximately $10 \%$ in both RCPs (see Figure A1). On the other hand, the lowest impact category (0.77-1.00) declines by $17 \%$ in both RCPs (see Figure 7).
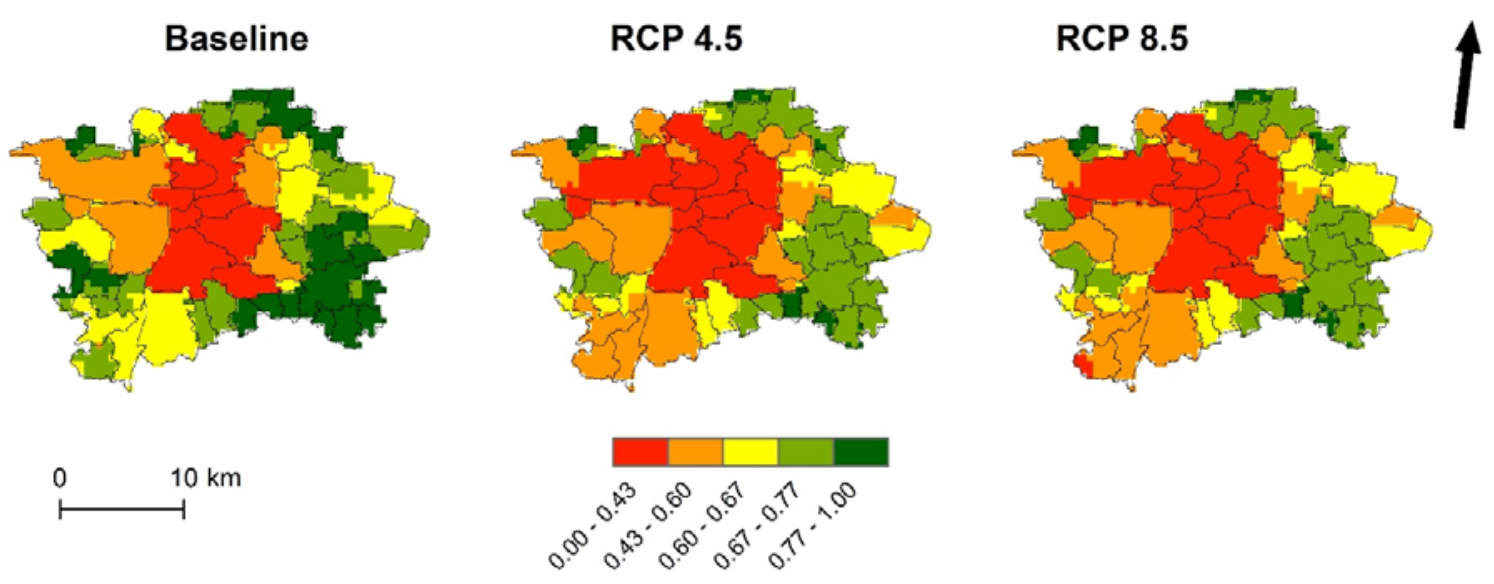

Figure 7. Prague in-city comparison of potential climate change impacts of heatwaves for the baseline (2015) and RCP 4.5 and RCP 8.5 (2030).

City of Brno

In Brno, the RCP 8.5 in 2030 indicates the largest extent of the high impact areas compared with the baseline. However, the trend in the rising extent of the high impact areas is also apparent under RCP 4.5. In 2030, under RCP 8.5, one-quarter of Brno has the highest impact (0.00-0.40) of heatwaves ( $23 \%$ under RCP 4.5 ), covering most of the city centre and stretching to the northeast (see Figure 8 ). The second highest impact category (0.40-0.61) increased in both scenarios by $4.6 \%$ (RCP 4.5 ) and $6.1 \%$ (RCP 8.5), respectively. Conversely, the lowest impact category (0.81-1.00) substantially declined under both scenarios by 13\% (RCP 4.5) and 16\% (RCP 8.5), respectively (see Figure A2). 
Baseline

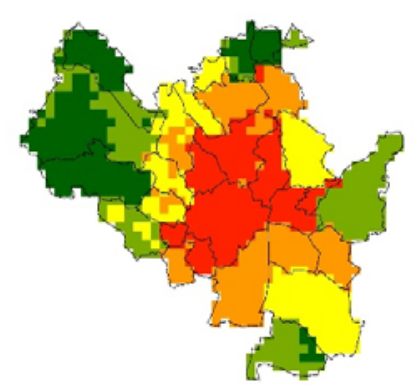

$\stackrel{0}{\stackrel{10}{1} \mathrm{~km}}$
RCP 4.5

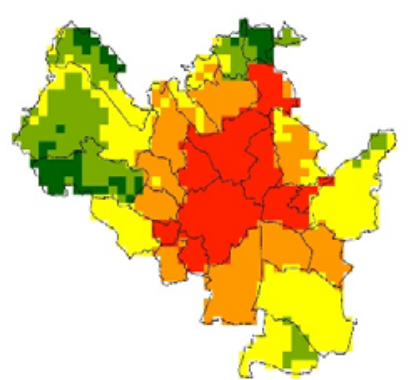

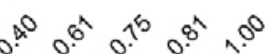

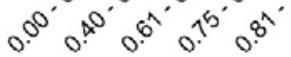

RCP 8.5

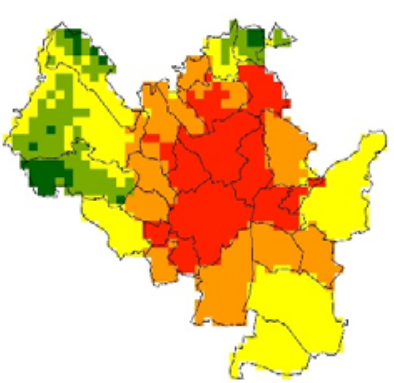

1

Figure 8. Brno in-city comparison of potential climate change impacts of heatwaves for the baseline (2015) and RCP 4.5 and RCP 8.5 (2030).

\section{City of Pilsen}

In Pilsen, the shift towards the highest impacts of heatwaves in the future (2030) is very significant and covers approximately half of the city's total area, stretching to the eastern part of the city (Figure 9). Compared with the baseline, the area of highest impact $(0.00-0.10)$ increases by $24.6 \%$ under RCP 4.5 and $27.5 \%$ under RCP 8.5 . The medium impact category $(0.13-0.15)$ is not represented under either RCP. However, the lowest impact category $(0.70-1.00)$ declined by $11.5 \%$ under both future scenarios (see Figure A3).

\section{Baseline}

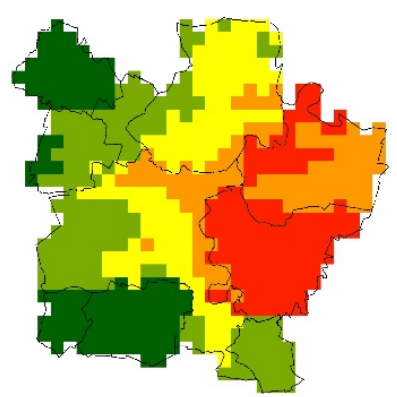

0

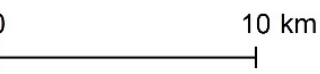

RCP 4.5

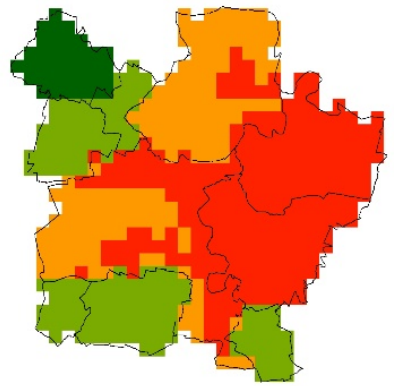

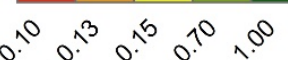

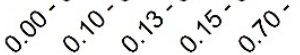

RCP 8.5

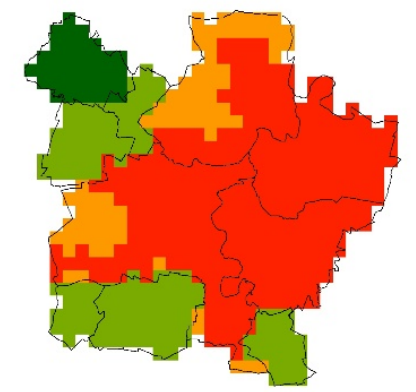

Figure 9. Pilsen in-city comparison of potential climate change impacts of heatwaves for the baseline (2015) and RCP 4.5 and RCP 8.5 (2030). 


\section{Discussion}

\subsection{Participatory Process}

This study focused on the comprehensive nature of vulnerability urban adaptation to climate change impacts, incorporating inputs from both spatial analyses, as well as participatory outcomes. In the presented analysis, we combined a science-based vulnerability assessment, in particular a potential climate change impact assessment of heatwaves, with the input of local knowledge based on participatory stakeholder workshops. The conducted spatially explicit assessment of potential heatwave impacts did not present an attempt at an exhaustive analysis, but rather an illustration of the benefits arising from combining multiple approaches in the process of developing climate change adaptation strategies for urban areas. The stakeholders' input was particularly beneficial for the prioritization of climate change-related problems and verification of the quantified assessment. For instance, during the participatory mapping in Prague, stakeholders assessed the areas most vulnerable to heatwaves (particularly specific areas in the city center and industrial areas), which provides verification of the results of the data-focused climate change impact mapping. During the participatory workshop in Pilsen, the problems related to heatwaves and UHIs did not receive the highest priority from stakeholders. This perception was confirmed by the inter-city comparison, where Pilsen shows the lowest impacts from heatwaves.

In the literature focused on transdisciplinary research and participatory approaches, many pragmatic arguments are presented for the engagement of stakeholders in climate change adaptation, for example [28,46-48]. Reed (2008) and Ross et al. (2015) speak of democratic rights and social justice reasons for local communities to participate in any processes concerning their own futures. Another important argument for stakeholder engagement is the mobilization of dialogue among important actors in the decision-making arena who can influence policy-making.

On the other hand, there are limitations to the participatory processes, for example, planning in "silos" and handling climate change like a separate issue, and not mainstreaming adaptation into relevant policy areas [49]. The constraints and limitations of participation in adaptation planning are mainly linked to: (i) lack of long-term stakeholder commitment [50]; (ii) communication between science and practice-the way global risks are translated to the local urban level [51]; (iii) uneven representation of stakeholders in the adaptation process [9]; (iv) power inequalities among stakeholders [9,52]; (v) shortage of skills and financial resources among municipal governments [53]; (vi) lack of institutional support and embedding of stakeholder participation [52]. Participation should be much more than just getting people to work together; engagement should have a deep meaning for them, allowing them to develop their own understanding of the problem and, most importantly, empowering them to take steps toward collective leadership [28]. The process of working through the vulnerability assessment cannot only rely on stakeholder participation. As demonstrated in this study, including an accurate quantification of the climate change impacts under discussion has also proved crucial for an improved understanding of their consequences and subsequent management.

\subsection{Spatial Assessment}

The study used a fuzzy gamma overlay approach (for more details, see $[45,54]$ ) to spatially analyze potential heatwave impacts in the three cities. In order to analyze differences between the three cities (Prague, Brno, Pilsen), the "inter-city" scale comparison was used. The inter-city comparison used the same quantile classification for each of the cities. The inter-city comparison shows the highest heatwave impacts in Brno, followed by Prague. In both cities, the hot-spot impacts are located in the city centers, are very high, and, together with the high impact category, currently cover $14.1 \%$ of Brno's area and $14 \%$ of Prague, with a rising trend in 2030. On the other hand, within the inter-city comparison, Pilsen shows the lowest impacts, without any proportion of the very high and high impact categories both currently and in 2030. From the regional perspective, the inter-city comparison provides a broader overview of the situation in Czech cities. 
For the purpose of urban planning, however, a more detailed scale is needed. Thus, in this study, we also presented an "in-city" comparison, which separately classifies categories for each of the cities. The in-city analysis shows more detailed trends in heatwave impacts in a particular city. For instance, in Pilsen, this approach allowed us to analyze the trend consisting of the highest impacts of heatwaves, which remains hidden when it comes to comparison between the cities (inter-city).

\subsection{Extreme Temperatures and Health}

Climate change can have substantial health effects, in particular, heatwaves are connected with well-being decline and vulnerable population mortality increase [17,18]. Buchin et al. (2016) [55] calculated heat-related deaths in the vulnerable age-group 65+ in Berlin. The modelling showed that the relative risk doubles with an increase of $1 \mathrm{~K}$ in ambient temperature.

Several studies have analysed heat-related mortality in the population of the Czech Republic $[18,56,57]$. For instance, the analysis focusing on the impacts of hot spells on mortality in 1986-2009 discovered a declining mortality trend despite the rising temperature. However, the primary cause of heat-related mortality decrease was probably due to substantial socio-economic development in the 1986-2009 period [57].

\subsection{Link to Urban Planning Practice}

Identification of heatwave impact hot-spots in the Czech cities under observation was intended to support spatial planning for urban adaptation. Spatial planning, as a policy arena, can support climate change adaptation and provide tools for mainstreaming climate change policies [58]. Integration of urban heat risk assessment into urban planning can be achieved in various ways. For instance, Icaza et al. (2016) [59] have proposed innovative tools (e.g., drift, layering, gameboard, and rhizome) for UHI assessment that can be incorporated into conventional spatial planning. In the case of Brno, the outcomes of the urban heatwave impact assessment have been integrated into an update of the Territorial Analytical Document of the City of Brno. A territorial analytical document (based on Act No. 183/2006 Coll.) is a spatial planning tool that provides information and analysis of the state and development of individual thematic areas of the city.

\subsection{Limitations of the Study}

The most substantial limitations of this study are linked to the availability of local-scale data. In constructing indices for climate change impacts, we are aware of the significance of data availability with respect to the reliability of those indices [60]. The situation becomes even more critical when it comes to regional or local levels, where compromises have to be made according to the available input data [20]. In this study, the main limitation in terms of data availability was associated with the smallest spatial unit for which the data for most indicators were available, i.e., the level of municipal districts. Although the data used were of the finest resolution available, a discrepancy between the resolution of climate change sensitivity indicators, such as population density and share of urban green spaces, and the spatial resolution of climate exposure data $(500 \times 500 \mathrm{~m})$, limited the spatial resolution of the results. In addition, we were limited to those particular climate change impact indicators for which sufficient data sources were available. Nevertheless, we argue that the most important aspects of heatwaves and subsequent urban heat island phenomena linked to heatwaves were sufficiently addressed and fell in line with other currently available studies [20].

\section{Conclusions}

The aim of this study was to present an example of heatwave impact assessments combined with a participative stakeholder process in order to reflect the importance of the participatory process and stakeholder engagement supporting strategic planning in vulnerability assessments of cities. The two methods applied in this research, i.e., participatory workshops and mapping of heatwave impacts, complement each other well. Participatory workshops were of great use in gathering local knowledge 
in terms of qualitative and quantitative data on climate change risks, while climate change impact mapping based on RCP projections enabled the spatial assessment of potential future impacts in the cities. Heatwaves and the development of urban heat islands pose significant challenges in urban areas, and as has been demonstrated in this study, their impacts are likely to worsen under future climate projections. Combined quantitative and participatory vulnerability assessment can support the preparation of climate change adaptation strategies in cities, which are becoming an indispensable component of urban planning.

Author Contributions: E.K.L. conceived and designed the study and wrote the paper; C.E.L.W. contributed to writing the paper; P.B. and Z.V.H. analyzed the data and performed the spatial analysis; P.Š., P.Z., and A.F. analyzed the climatic data; D.V. contributed to the design of the study.

Acknowledgments: This research was supported by a grant from Iceland, Liechtenstein, and NorwayUrbanAdapt project (EHP-CZ02-OV-1-036-2015), supported by the Ministry of Education, Youth and Sports of the Czech Republic within the National Sustainability Program I (NPU I), grant number LO1415 and by the Czech Technology Agency (grant number TL01000238). P.Z. was supported by the project System for Monitoring and Forecast of Impacts of Agricultural Drought (QJ1610072) of the National Agency for Agricultural Research, and P.Š. was supported by the Czech Science Foundation, project No. 17-10026S. We would like to thank five anonymous reviewers for their comments.

Conflicts of Interest: The authors declare no conflicts of interest.

\section{Appendix A}

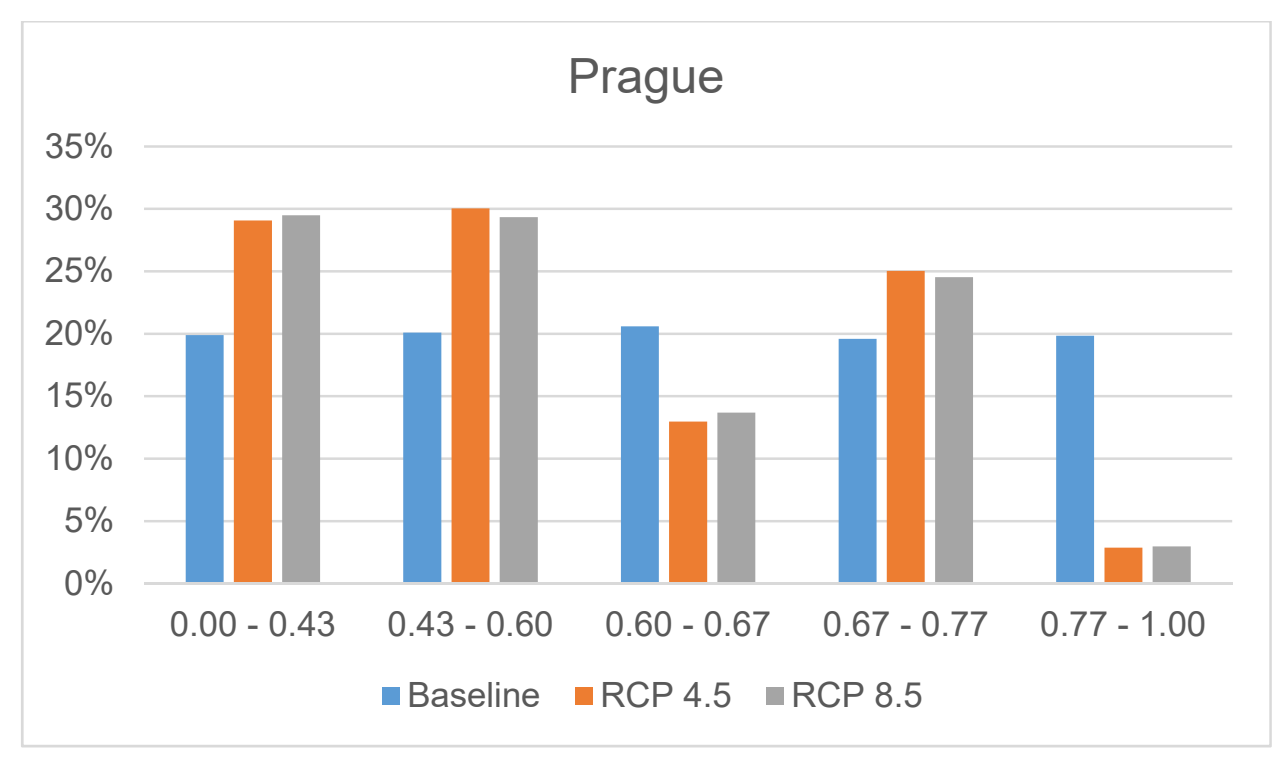

Figure A1. In-city comparison of potential heatwave impact categories in Prague for the baseline (2015), RCP 4.5, and RCP 8.5 . 


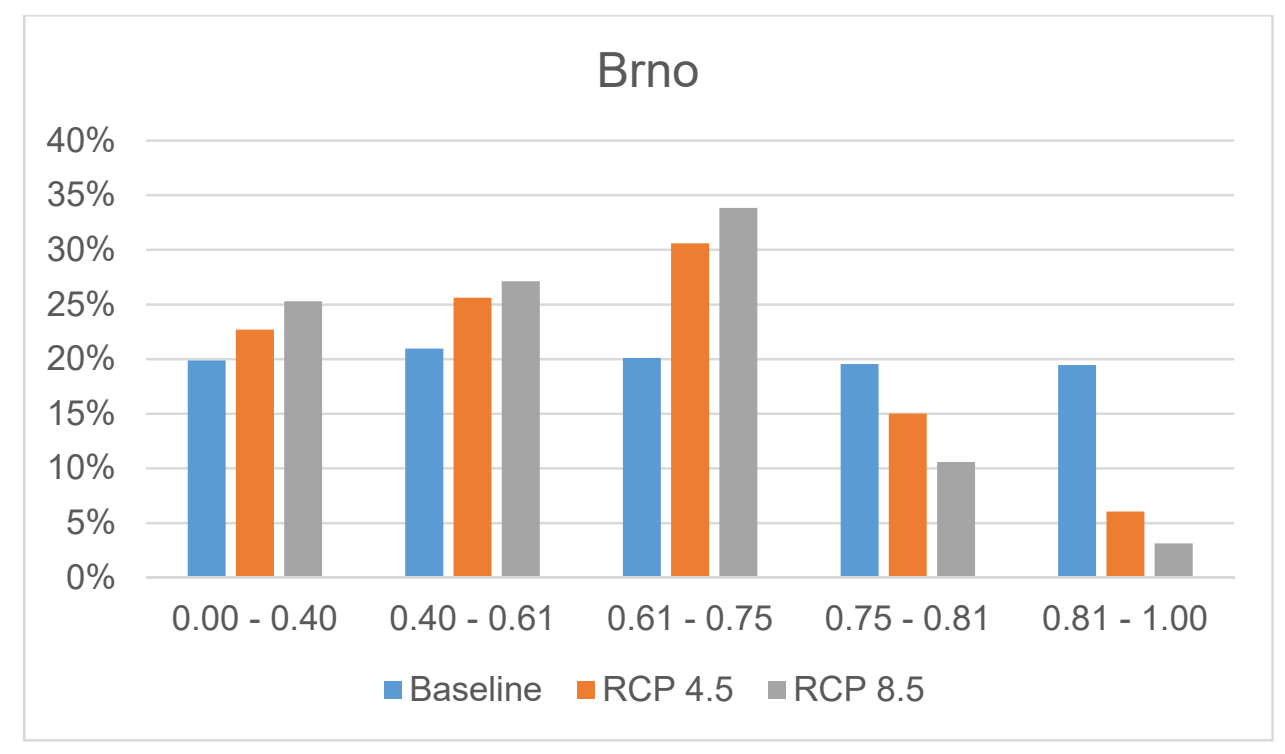

Figure A2. In-city comparison of potential heatwave impact categories in Brno for the baseline (2015), RCP 4.5, and RCP 8.5 .

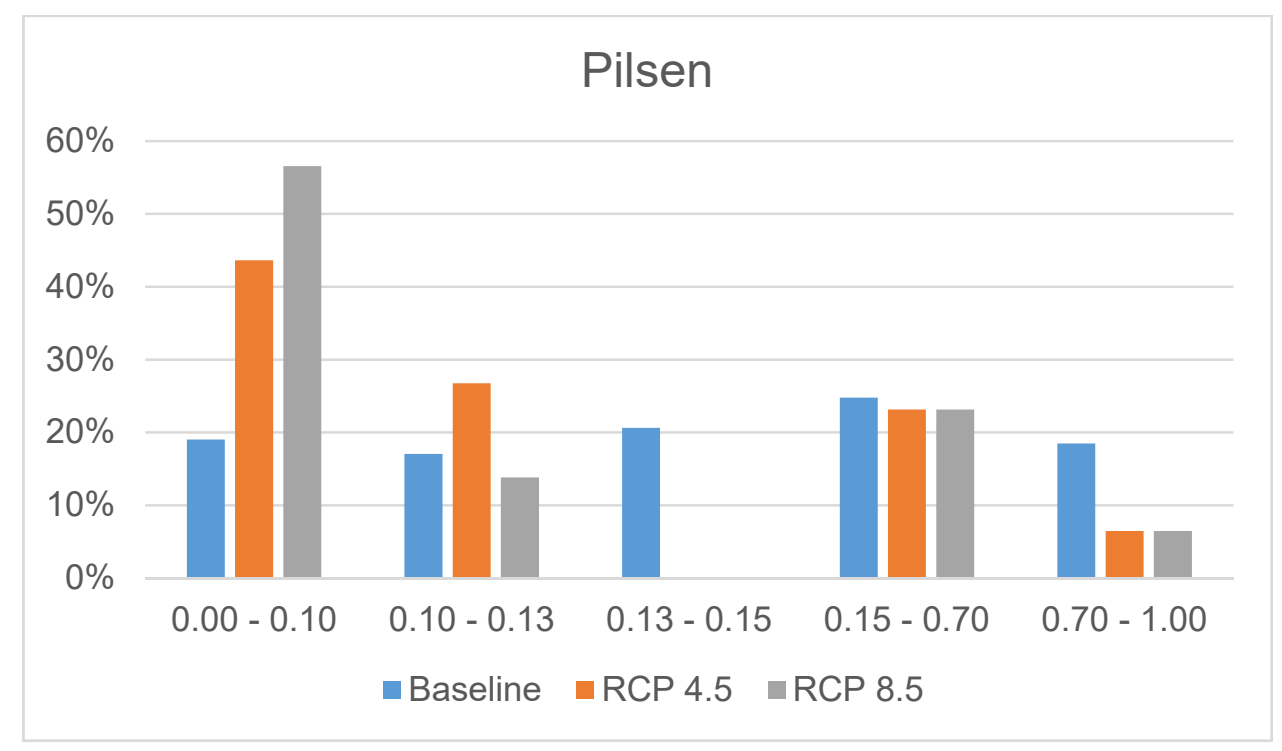

Figure A3. In-city comparison of potential heatwave impact categories in Pilsen for the baseline (2015), RCP 4.5, and RCP 8.5.

\section{References}

1. Andersson-Skold, Y.; Thorsson, S.; Rayner, D.; Lindberg, F.; Janhall, S.; Jonsson, A.; Moback, U.; Bergman, R.; Granberg, M. An integrated method for assessing climate-related risks and adaptation alternatives in urban areas. Clim. Risk Manag. 2015, 7, 31-50. [CrossRef]

2. Andersson, E. Urban landscapes and sustainable cities. Ecol. Soc. 2006, 11, 34. [CrossRef]

3. European Environment Agency (EEA). Urban Adaptation to Climate Change in Europe; European Environment Agency: København K, Denmark, 2012; ISBN 9789292133085.

4. Geneletti, D.; Zardo, L. Ecosystem-based adaptation in cities: An analysis of European urban climate adaptation plans. Land Use Policy 2016, 50, 38-47. [CrossRef]

5. Jenkins, K.; Hall, J.; Glenis, V.; Kilsby, C.; McCarthy, M.; Goodess, C.; Smith, D.; Malleson, N.; Birkin, M. Probabilistic spatial risk assessment of heat impacts and adaptations for London. Clim. Chang. 2014, 124, 105-117. [CrossRef] 
6. Brooks, N.; Adger, W.N.; Kelly, P.M. The determinants of vulnerability and adaptive capacity at the national level and the implications for adaptation. Glob. Environ. Chang. 2005, 15, 151-163. [CrossRef]

7. Salas, J.; Yepes, V. Urban vulnerability assessment: Advances from the strategic planning outlook. J. Clean. Prod. 2018, 179, 544-558. [CrossRef]

8. Absar, S.M.; Preston, B.L. Extending the Shared Socioeconomic Pathways for sub-national impacts, adaptation, and vulnerability studies. Glob. Environ. Chang. 2015, 33, 83-96. [CrossRef]

9. Shi, L.; Chu, E.; Anguelovski, I.; Aylett, A.; Debats, J.; Goh, K.; Schenk, T.; Seto, K.C.; Dodman, D.; Roberts, D.; et al. Roadmap towards justice in urban climate adaptation research. Nat. Clim. Chang. 2016, 6, 131-137. [CrossRef]

10. Hallegatte, S.; Corfee-Morlot, J. Understanding climate change impacts, vulnerability and adaptation at city scale: An introduction. Clim. Chang. 2011, 104, 1-12. [CrossRef]

11. Jiang, L.; O'Neill, B.C. Global urbanization projections for the Shared Socioeconomic Pathways. Glob. Environ. Chang. 2017, 42, 193-199. [CrossRef]

12. CZSO (Czech Statistical Office). Demographic Yearbook of the Czech Republic-2014; CZSO: Prague, Czech Republic, 2015.

13. Kc, S.; Lutz, W. Demographic scenarios by age, sex and education corresponding to the SSP narratives. Popul. Environ. 2014, 35, 243-260. [CrossRef]

14. Runhaar, H.; Mees, H.; Wardekker, A.; van der Sluijs, J.; Driessen, P.P.J. Adaptation to climate change-related risks in Dutch urban areas: Stimuli and barriers. Reg. Environ. Chang. 2012, 12, 777-790. [CrossRef]

15. Guerreiro, S.B.; Dawson, R.J.; Kilsby, C.; Lewis, E.; Ford, A. Future heat-waves, droughts and floods in 571 European cities. Environ. Res. Lett. 2018, 13. [CrossRef]

16. Revi, A.; Satterthwaite, D.E.; Aragón-Durand, F.; Field, C.B. Urban Areas. In Climate Change 2014: Impacts, Adaptation, and Vulnerability. Part A: Global and Sectoral Aspects; Contribution of Working Group II to the Fifth Assessment Report of the Intergovernmental Panel on Climate Change; Cambridge University Press: Cambridge, UK, 2014.

17. European Environment Agency (EEA). Climate Change, Impacts and Vulnerability in Europe 2016: An Indicator-Based Report; European Environment Agency: København K, Denmark, 2017; Volume 1/2017, ISBN 978-92-9213-835-6. Available online: https://www.eea.europa.eu/publications/climate-changeimpacts-and-vulnerability-2016 (accessed on 5 June 2018).

18. World Health Organization (WHO). Improving Environment and Health in Europe: How Far Have We Gotten? WHO Regional Office for Europe: Copenhagen, Denmark, 2015; ISBN 9789289050876.

19. CZSO (Czech Statistical Office). Population and Housing CENSUS-2011; CZSO: Prague, Czech Republic, 2011.

20. Rannow, S.; Loibl, W.; Greiving, S.; Gruehn, D.; Meyer, B.C. Potential impacts of climate change in Germany-Identifying regional priorities for adaptation activities in spatial planning. Landsc. Urban Plan. 2010, 98, 160-171. [CrossRef]

21. Leal Filho, W.; Echevarria Icaza, L.; Neht, A.; Klavins, M.; Morgan, E.A. Coping with the impacts of urban heat islands. A literature based study on understanding urban heat vulnerability and the need for resilience in cities in a global climate change context. J. Clean. Prod. 2018, 171, 1140-1149. [CrossRef]

22. Yohe, G.; Leichenko, R. Adopting a risk-based approach. Ann. N. Y. Acad. Sci. 2010, 1196, 29-40. [CrossRef] [PubMed]

23. Kostas, P.; Bithas, M.C. Environmentally sustainable cities. Critical review and operational conditions. Sustain. Dev. 2006, 14, 177-189. [CrossRef]

24. Leach, J.M.; Lee, S.E.; Hunt, D.V.L.; Rogers, C.D.F. Improving city-scale measures of livable sustainability: A study of urban measurement and assessment through application to the city of Birmingham, UK. Cities 2017, 71, 80-87. [CrossRef]

25. Lombardi, M.; Laiola, E.; Tricase, C.; Rana, R. Toward urban environmental sustainability: The carbon footprint of Foggia's municipality. J. Clean. Prod. 2018, 186, 534-543. [CrossRef]

26. Reckien, D.; Salvia, M.; Heidrich, O.; Church, J.M.; Pietrapertosa, F.; De Gregorio-Hurtado, S.; D’Alonzo, V.; Foley, A.; Simoes, S.G.; Lorencová, E.K.; et al. How are cities planning to respond to climate change? Assessment of local climate plans from 885 cities in the EU-28. J. Clean. Prod. 2018. [CrossRef]

27. Romero Lankao, P.; Qin, H. Conceptualizing urban vulnerability to global climate and environmental change. Curr. Opin. Environ. Sustain. 2011, 3, 142-149. [CrossRef] 
28. Ross, H.; Shaw, S.; Rissik, D.; Cliffe, N.; Chapman, S.; Hounsell, V.; Udy, J.; Trinh, N.T.; Schoeman, J. A participatory systems approach to understanding climate adaptation needs. Clim. Chang. 2015, 129, $27-42$. [CrossRef]

29. Rossignol, N.; Delvenne, P.; Turcanu, C. Rethinking Vulnerability Analysis and Governance with Emphasis on a Participatory Approach. Risk Anal. 2015, 35, 129-141. [CrossRef] [PubMed]

30. Birkmann, J.; Cardona, O.D.; Carreño, M.L.; Barbat, A.H.; Pelling, M.; Schneiderbauer, S.; Kienberger, S.; Keiler, M.; Alexander, D.; Zeil, P.; et al. Framing vulnerability, risk and societal responses: The MOVE framework. Nat. Hazards 2013, 67, 193-211. [CrossRef]

31. Kumar, P.; Geneletti, D.; Nagendra, H. Spatial assessment of climate change vulnerability at city scale: A study in Bangalore, India. Land Use Policy 2016, 58, 514-532. [CrossRef]

32. Toth, F.L.; Hizsnyik, E. Managing the inconceivable: Participatory assessments of impacts and responses to extreme climate change. Clim. Chang. 2008, 91, 81-101. [CrossRef]

33. Swart, R.J.; Fons, J.; Geertsema, W. Urban Vulnerability Indicators: A Joint Report of ETC-CCA and ETC-SIA; ETC CCA: Copenhagen, Denmark, 2012.

34. Füssel, H.M.; Klein, R.J.T. Climate change vulnerability assessments: An evolution of conceptual thinking. Clim. Chang. 2006, 75, 301-329. [CrossRef]

35. Luckenkotter, J.; Lindner, C.; Greiving, S. Methodology for an integrated climate change vulnerability assessment. In European Climate Vulnerabilities and Adaptation: A Spatial Planning Perspective; Wiley-Blackwell: Chichester, UK, 2013.

36. Nelson, R.; Kokic, P.; Crimp, S.; Meinke, H.; Howden, S.M. The vulnerability of Australian rural communities to climate variability and change: Part I-Conceptualising and measuring vulnerability. Environ. Sci. Policy 2010, 13, 8-17. [CrossRef]

37. Van Vuuren, D.P.; Den Elzen, M.G.J.; Lucas, P.L.; Eickhout, B.; Strengers, B.J.; Van Ruijven, B.; Wonink, S.; Van Houdt, R. Stabilizing greenhouse gas concentrations at low levels: An assessment of reduction strategies and costs. Clim. Chang. 2007, 81, 119-159. [CrossRef]

38. Riahi, K.; Grübler, A.; Nakicenovic, N. Scenarios of long-term socio-economic and environmental development under climate stabilization. Technol. Forecast. Soc. Chang. 2007, 74, 887-935. [CrossRef]

39. Štěpánek, P.; Zahradníček, P.; Huth, R. Interpolation techniques used for data quality control and calculation of technical series: An example of a Central European daily time series. Idojaras 2011, 115, 87-98.

40. Štěpánek, P.; Zahradníček, P.; Farda, A. Experiences with data quality control and homogenization of daily records of various meteorological elements in the Czech Republic in the period 1961-2010. Idojaras 2013, 117, 123-141.

41. Déqué, M. Frequency of precipitation and temperature extremes over France in an anthropogenic scenario: Model results and statistical correction according to observed values. Glob. Planet. Chang. 2007, 57, 16-26. [CrossRef]

42. Štěpánek, P.; Zahradníček, P.; Farda, A.; Skalák, P.; Trnka, M.; Meitner, J.; Rajdl, K. Projection of drought-inducing climate conditions in the Czech Republic according to Euro-CORDEX models. Clim. Res. 2016, 70, 179-193. [CrossRef]

43. Royé, D. The effects of hot nights on mortality in Barcelona, Spain. Int. J. Biometeorol. 2017, 61, $2127-2140$. [CrossRef] [PubMed]

44. Liu, X.P.; Zhang, J.Q.; Tong, Z.J.; Bao, Y. GIS-based multi-dimensional risk assessment of the grassland fire in northern China. Nat. Hazards 2012, 64, 381-395. [CrossRef]

45. Araya-Muñoz, D.; Metzger, M.J.; Stuart, N.; Wilson, A.M.W.; Alvarez, L. Assessing urban adaptive capacity to climate change. J. Environ. Manag. 2016, 183, 314-324. [CrossRef] [PubMed]

46. Kok, K.; Biggs, R.; Zurek, M. Methods for developing multiscale participatory scenarios: Insights from Southern Africa and Europe. Ecol. Soc. 2007, 12, 8. [CrossRef]

47. Walz, A.; Lardelli, C.; Behrendt, H.; Grêt-Regamey, A.; Lundström, C.; Kytzia, S.; Bebi, P. Participatory scenario analysis for integrated regional modelling. Landsc. Urban Plan. 2007, 81, 114-131. [CrossRef]

48. Reed, S.O.; Friend, R.; Toan, V.C.; Thinphanga, P.; Sutarto, R.; Singh, D. “Shared learning” for building urban climate resilience-Experiences from Asian cities. Environ. Urban. 2013, 25, 393-412. [CrossRef]

49. Measham, T.G.; Preston, B.L.; Smith, T.F.; Brooke, C.; Gorddard, R.; Withycombe, G.; Morrison, C. Adapting to climate change through local municipal planning: Barriers and challenges. Mitig. Adapt. Strateg. Glob. Chang. 2011, 16, 889-909. [CrossRef] 
50. Chu, E.; Anguelovski, I.; Carmin, J. Inclusive approaches to urban climate adaptation planning and implementation in the Global South. Clim. Policy 2014, 14, 417-441. [CrossRef]

51. Hardoy, J.; Romero Lankao, P. Latin American cities and climate change: Challenges and options to mitigation and adaptation responses. Curr. Opin. Environ. Sustain. 2011, 3, 158-163. [CrossRef]

52. Reed, M.S. Stakeholder participation for environmental management: A literature review. Biol. Conserv. 2008, 141, 2417-2431. [CrossRef]

53. Hardoy, J.; Ruete, R. Incorporating climate change adaptation into planning for a liveable city in Rosario, Argentina. Environ. Urban. 2013, 25, 339-360. [CrossRef]

54. Araya-Muñoz, D.; Metzger, M.J.; Stuart, N.; Wilson, A.M.W.; Carvajal, D. A spatial fuzzy logic approach to urban multi-hazard impact assessment in Concepción, Chile. Sci. Total Environ. 2017, 576, 508-519. [CrossRef] [PubMed]

55. Buchin, O.; Hoelscher, M.T.; Meier, F.; Nehls, T.; Ziegler, F. Evaluation of the health-risk reduction potential of countermeasures to urban heat islands. Energy Build. 2016, 114, 27-37. [CrossRef]

56. Urban, A.; Burkart, K.; Kyselý, J.; Schuster, C.; Plavcová, E.; Hanzlíková, H.; Štěpànek, P.; Lakes, T. Spatial patterns of heat-related cardiovascular mortality in the Czech Republic. Int. J. Environ. Res. Public Health 2016, 13, 284. [CrossRef] [PubMed]

57. Kyselý, J.; Plavcová, E. Declining impacts of hot spells on mortality in the Czech Republic, 1986-2009: Adaptation to climate change? Clim. Chang. 2012, 113, 437-453. [CrossRef]

58. Yiannakou, A.; Salata, K.-D. Adaptation to Climate Change through Spatial Planning in Compact Urban Areas: A Case Study in the City of Thessaloniki. Sustainability 2017, 9, 271. [CrossRef]

59. Icaza, L.E.; Van Den Dobbelsteen, A.; Van Der Hoeven, F. Integrating urban heat assessment in urban plans. Sustainability 2016, 8, 320. [CrossRef]

60. Nelson, R.; Kokic, P.; Crimp, S.; Martin, P.; Meinke, H.; Howden, S.M.; de Voil, P.; Nidumolu, U. The vulnerability of Australian rural communities to climate variability and change: Part II-Integrating impacts with adaptive capacity. Environ. Sci. Policy 2010, 13, 18-27. [CrossRef]

(C) 2018 by the authors. Licensee MDPI, Basel, Switzerland. This article is an open access article distributed under the terms and conditions of the Creative Commons Attribution (CC BY) license (http:/ / creativecommons.org/licenses/by/4.0/). 